\title{
Power and Leadership
}

\author{
Marius van Dijke \\ ${ }^{a}$ Rotterdam School of Management, Erasmus University, Rotterdam, The Netherlands \\ ${ }^{b}$ Nottingham Business School, Nottingham Trent University, Nottingham, UK \\ Corresponding author: Marius van Dijke (mvandijke@rsm.nl), Erasmus Center of Behavioural Ethics, \\ Rotterdam School of Management, Erasmus University Rotterdam, P.O. Box 1738, 3000 DR, Rotterdam, \\ The Netherlands
}

\begin{abstract}
Social collectives often grant power to leaders so they can facilitate collective performance. At present, there is no comprehensive overview of how power influences the effectiveness of different influence mechanisms leaders use to achieve this goal. To help develop such an overview, I review recent research on the positive and negative effects of power on some of these influence mechanisms: leaders' punishment of norm transgressions, concern for followers, and procedural fairness enactment. I also highlight the role of individual differences and contextual factors in these processes. I end by discussing implications and future research directions.
\end{abstract}

\section{Introduction}

Leadership refers to interactions between an individual (the leader) and other members of a social collective (followers) through which the leader aims to improve collective performance, specifically by motivating followers to contribute to the collective, facilitating collective decision-making, and coordinating followers' efforts [1,2]. Scholars often focus on inspiring, empowering, and showing concern for followers as leadership actions that promote collective performance [3,4]. However, leaders also frequently control resources valued by followers, giving leaders power over followers [5]. For instance, in work contexts, leaders may control followers' salary and promotion opportunities.

Power is an important yet sometimes underappreciated element of leader's collectiveperformance-promoting actions. Meta-analyses show that clarifying expectations combined with rewards for meeting these expectations is in many ways as effective in motivating followers to contribute to collective performance as inspiring, empowering, or showing concern for followers [6-8]. Even punishing followers who fail agreed-upon performance targets promotes subsequent performance when punishment is proportionate [9]. Thus, power can be used to motivate followers to contribute to collective performance.

There is no comprehensive overview of how power influences the effectiveness of different mechanisms that leaders use to facilitate collective performance. Existing reviews on power and leadership give a partial picture: power makes leaders act in self-interested ways when self-interested goals are salient or when their power position is threatened [10]. Self-interest likely makes leaders less effective in promoting collective performance [11]. 
To broaden the picture (Figure 1), I review the following topics in recent research on leadership and power: how leader's power influences the effectiveness of their punishment of norm transgressions and showing concern for followers in stimulating collective performance; the moderating role of personality dispositions in the aforementioned effects of power; and the role of contextual factors, including the influence of followers and higher-ranked others in said effects of power.

\section{Power and leader's focus on collective performance}

Punishment of norm transgressions. One way leaders influence collective performance is by punishing followers who transgress moral norms (e.g., stealing, harming others). Such punishment communicates that the organization has high moral standards, which increases followers' willingness to contribute to the collective [12]. Leaders may punish moral transgressions because they feel such transgressions deserve punishment (i.e., "just deserts") or to deter transgressors and others. Power may influence the operation of both motives: high(vs. low-) power leaders dispense more severe punishments because high power increases confidence in the correctness of one's beliefs about the transgressor's character [13] or makes one less ambiguous about moral standards [14]. This effect even generalizes to bystanders: high- (vs. low-) power bystanders confront transgressors more, avoid transgressors less, and offer more social support to victims of incivility [15]. Finally, high (vs. low) power strengthens deterrence motives [16].

Power may also influence whether leaders punish transgressions of moral norms instrumentally: leaders punish less severely misconduct that benefits (vs. harms) the organization [17]. Furthermore, when observing unethical practices, highly (vs. lowly) ranked organization members engage less in principled dissent because they identify strongly with their organization [18].

That high (vs. low) power increases leader's focus on just deserts and deterrence, and possibly instrumental use of punishment does not imply that high (vs. low) power always makes leader's use of punishment more effective in focusing followers on the collective. Followers respond uncooperatively to punishment justified as deterrents (compared to justdesert or even no justifications [19]). Furthermore, transgressions of moral standards may be less clear to followers than to leaders [14] and followers may care less about collective performance than leaders [18]. Thus followers may view punishments from high-power leaders as too severe (e.g. when just desert driven) or too lenient (e.g. when misconduct benefits the organization), and respond uncooperatively [9].

Concern for followers. By showing high concern for followers, leaders stimulate them to contribute to the collective [6]. Leaders who exploit followers to achieve their selfish ends make followers less inclined to contribute [11]. Having high (vs. low) power may influence leader's concern for followers. Various experiments, some using economic games, show that having high (vs. low) power makes leaders care less about their followers' interests (e.g., [20,21]). This suggests that high (vs. low) power reduces leader's effectiveness in promoting collective performance. Findings of research in naturalistic settings converge less. An Experience Sampling (ESM) study in work organizations showed that feeling more (vs. less) powerful predicts abusive leader behaviors towards followers (in turn, these behaviors predict reduced well-being of leaders; [22]; see also [23]). However, another ESM study involving a sample of the general US population found that momentarily feeling more (vs. less) powerful predicted a heightened sense of responsibility [24]. 
One explanation for these divergent results is that economic games and work interactions involve strong competition between leaders and followers (relative to power in everyday life; see [25]), such that, in these settings, leaders construe power as means to benefit their own interests (cf. [26]). Indeed, when construed as enabling the pursuit of self-centered goals, power increases selfishness, tolerance of own and others' corruption, and aversion to costly punishments of transgressions. When construed as involving responsibility to benefit others, power reduces selfishness and tolerance of own and others' corruption, and increases costly punishment [27]. When construed as allowing one to do what one finds important, power also leads to disregarding others' advice, but not when construed as responsibility for necessary tasks [28].

Thus, construal (not level) of power may explain when leaders use their power to focus their followers on the collective [29]. In everyday life, power is often construed as involving responsibility [24]. This construal is made more likely by some factors: when power holders adopt a cognitive focus on another person (vs. on the self; [30]), when they strongly identify with the organization [31], and when they are removed from decision consequences (i.e., in intergenerational decision-making; [32]).

\section{Power, collective focus, and individual differences between leaders}

Power and procedural fairness enactment. One type of leadership behavior that reflects concern for followers and that has been well studied in relation to power is procedural fairness, that is: making fair decisions about followers' outcomes (e.g., salary, promotion opportunities), ensuring, for instance, follower's voice in the leader's decisions, correctability of a decision, and suppression of decision biases [33]. Leaders who ensure procedural fairness motivate followers to contribute to the collective [34-36]. This effect emerges particularly when leaders have high (vs. low) power over followers, presumably because high (vs. low) power makes followers view leaders as more responsible for the fairness of decisions [37].

Notwithstanding this effectiveness, leaders may not consider ensuring fairness a central goal. Unless they are specifically rewarded for acting fairly, a high workload prevents leaders from enacting fairness [38]. High (vs. low) power strengthens the link between central goals and behavior $[39,40]$. This effect of power is relevant to procedural fairness enactment: having high (vs. low) power makes leaders behave less procedurally fair, but only if they lack concern for others as a central dispositional goal [41]. Relatedly, high- (vs. low-) power leaders explain their decisions more candidly and respectfully (i.e., they display interactional fairness, a kind of fairness related to procedural fairness) when taking the perspective of others is a central goal [42].

Power, personality, and collective performance. It is well-established that power strengthens the link between central dispositional goals and behavior, making, for instance, prosocially oriented individuals act in more prosocial ways and selfish individuals act more selfishly (e.g., [39,40]). Regarding leadership, this effect of power may even have downstream consequences for actions of collectives. For instance, the political ideology (liberal vs. conservative) of CEOs of large firms is more predictive of the firms' corporate social responsibility practices among high- (vs. low-) power CEOs [43].

Another way in which power may emphasize the personality traits relevant to promoting collective performance is through the leadership promotion process. Possessing leadership capabilities (e.g., intelligence) makes one relatively likely to emerge as leader [44]. Yet, characteristics that can undermine collective performance can also facilitate climbing to leadership positions; for instance, confident and forceful behavior promotes higher positions in 
hierarchies [45]. However, followers participate less in discussions with a powerful individual who exhibits (vs. does not exhibit) confidence, and would even defer to powerful, confidenceexuding individuals when those individuals are wrong [46].

In contrast, humility (a willingness to view oneself accurately, appreciate others' strengths and contributions, and being open to new ideas and feedback) may decrease the chance of getting a leadership position. However, humble leadership predicts heightened follower [47] and team performance $[48,49]$, and in the case of CEO humility, more effective operation of the top management team and subsequent stronger firm performance [50].

\section{Power, contextual influences, and collective performance}

Goals are often defined by the situation, and power may make people more effective in striving towards situationally defined goals $[51,52]$. This claim may also apply to situational goals that prescribe behavior intended to support the collective and its members. Organization members who feel powerful (vs. powerless) respond to factors that stimulate benefitting the collective and its members (i.e., high procedural fairness) with behavior that does exactly this [53]. These findings are relevant for leadership because showing concern for followers stimulates them to contribute to the collective in turn.

Power and context relate in other ways to leader's effectiveness in promoting collective performance. Leader-follower interactions are not a one-way street: followers also influence their leaders (e.g., [54]). Followers decrease leader's abuse by reducing leader's power over them, specifically by either forming coalitions with other followers or increasing their value for the leader's central goals [23]. Followers' influence is not limited to power-equalizing actions. Leaders make increasingly self-interested allocations over time when followers offer positive feedback that ignores whether their leader has acted self-interestedly. However, leaders subsequently act in less self-interested ways when feedback accurately reflects the leader's self-interested actions [55]. This effect of feedback accuracy occurs even when only one follower provides accurate feedback while the majority provides compliant feedback [56].

Those higher up the hierarchy also influence leader's concern for followers. Leaders act in more self-interested ways when they feel unfairly treated by the organization [57], and they abuse followers more when senior management acts in norm-deviating and antisocial ways [58]. Leaders act more procedurally fairly when they are treated with procedural fairness [59]. These trickle-down effects are usually explained in terms of social learning and generalized reciprocity, although there is little direct evidence for the operation of these mediational processes [60]. More complex processes are also at play. For instance, leaders only emulate senior leaders' enactment of procedural fairness when they define themselves in terms of their relationship with senior leaders; when they don't, then leaders distance themselves from such fairness enactment [61].

\section{Discussion and Conclusion}

Although this review provides little evidence that high (vs. low) power in itself makes leaders more (or less) effective in promoting collective performance, the conclusion that high (vs. low) power makes leaders act more on personality-based goals has important implications for designing leadership selection systems. For instance, humble individuals may be informally viewed as having less leadership potential than dominant individuals; nevertheless, humility is often a more effective leader characteristic than dominance.

That high (vs. low) power makes leaders more effective in acting upon situationally 
defined goals suggests that organizations should be designed to promote collective performance (e.g., via high procedural fairness), not to undermine it (e.g., via overly strong interpersonal competition). Organizations should also explicitly define power roles not as an opportunity to do what one wants but in terms of responsibility.

Much power research has deemphasized the interpersonal nature of power by studying effects of recall manipulations or role assignments on outcomes isolated from interactions $[26,62,63]$. This review provides context to these findings. Field research shows that high (vs. low) power predicts leader's abusive behavior, which then predicts subsequent decreased leader well-being [22]. Furthermore, in addition to leader's power, followers and higher-level leaders influence whether leaders show concern for followers. It should be noted that almost all reviewed field research used designs that preclude drawing causal conclusions. Such research should make better use of methodological innovations, such as econometric tools [64].

Finally, this review identifies questions for future research. Do differences in interpersonal competition explain the inconsistent findings on the role of power in making leaders show less concern for followers? What is the nature of power as responsibility, given that high identification leads to construing power as involving responsibility [31] and responsibility decreases principled dissent [17]? Research should also zoom in on the role of power in leaders' display of inspirational behaviors and empowerment of followers, and the role of the moderators identified in this review in these effects (Figure 1). Such research would greatly contribute to understanding the interrelationships of power and leadership.

\section{Acknowledgements}

I thank Leander De Schutter, Gijs van Houwelingen, Laura Giurge, and Michelle Xue Zheng for their valuable comments on drafts of this paper. I thank Yiran Guo for her help in identifying studies to include in the review and formatting the paper.

\section{Reference List}

[1] R. Hogan, R.B. Kaiser, What we know about leadership., Rev. Gen. Psychol 2005, 9: 169-180. doi:10.1037/1089-2680.9.2.169.

[2] G.A. Yukl, Leadership in organizations (Global ed.), Harlow Pearson. 2013.

[3] B.J. Avolio, B.M. Bass, Developing potential across a full range of Leadership Tm: Cases on transactional and transformational leadership, Psychology Press, 2001.

[4] L. D'Innocenzo, J.E. Mathieu, M.R. Kukenberger, A meta-analysis of different forms of shared leadership-team performance relations, J. Manag 2016, 42: 1964-1991. doi: $10.1177 / 0149206314525205$.

[5] J.C. Magee, A.D. Galinsky, Social hierarchy: The self-reinforcing nature of power and status, Acad. Manag. Ann. 2008, 2: 351-398. doi:10.1080/19416520802211628.

[6] M. Ceri-Booms, P.L. Curseu, L.A.G. Oerlemans, Task and person-focused leadership behaviors and team performance: A meta-analysis, Hum. Resour. Manag. Rev. 2017, 27: 178-192. doi:10.1016/j.hrmr.2016.09.010.

*This meta-analysis shows the equivalence in effectiveness between leadership styles that build on power and other leadership styles, such as those based on inspiration or developing high-quality interpersonal relations with followers.

[7] C.S. Burke, K.C. Stagl, C. Klein, G.F. Goodwin, E. Salas, S.M. Halpin, What type of leadership behaviors are functional in teams? A meta-analysis, Leadersh. Q. 2006, 17: 288-307. doi:10.1016/j.leaqua.2006.02.007.

[8] T.A. Judge, R.F. Piccolo, Transformational and transactional leadership: a meta-analytic test of 
their relative validity, J. Appl. Psychol. 2004, 89: 755-768. doi:10.1037/0021-9010.89.5.755.

[9] P. Podsakoff, W. Bommer, N. Podsakoff, S. MacKenzie, Relationships between leader reward and punishment behavior and subordinate attitudes, perceptions, and behaviors: A meta-analytic review of existing and new research, Organ. Behav. Hum. Decis. Process. 2006, 99: 113-142. doi:10.1016/j.obhdp.2005.09.002.

[10] M.J. Williams, Serving the self from the seat of power: goals and threats predict leaders' selfinterested behavior, J. Manag. 2014, 40: 1365-1395. doi:10.1177/0149206314525203.

[11] E.A. Schmid, A. P. Verdorfer, C. Peus, Shedding light on leaders' self-interest: theory and measurement of exploitative leadership., J. Manag. 2019, 45: 1401-1433.

[12] Skarlicki, D. P., Kulik, C. T., Third-party reactions to employee (mis) treatment: A justice perspective, Res. Organ. Behav. 2004, 26: 183-229. doi:10.1016/S0191-3085(04)26005-1

[13] J.-W. van Prooijen, J. Coffeng, M. Vermeer, Power and retributive justice: How trait information influences the fairness of punishment among power holders, J. Exp. Soc. Psychol. 2014, 50: 190201. doi:10.1016/j.jesp.2013.10.004.

[14] S.S. Wiltermuth, F.J. Flynn, Power, moral clarity, and punishment in the workplace, Acad. Manage. J. 2013, 56: 1002-1023. doi:10.5465/amj.2010.0960.

[15] M.S. Hershcovis, L. Neville, T.C. Reich, A.M. Christie, L.M. Cortina, J.V. Shan, Witnessing wrongdoing: The effects of observer power on incivility intervention in the workplace, Organ. Behav. Hum. Decis. Process. 2017, 142: 45-57. doi:10.1016/j.obhdp.2017.07.006.

[16] P.T.M. Desmet, N. Hoogervorst, M. Van Dijke, Prophets vs. profits: How market competition influences leaders' disciplining behavior towards ethical transgressions, Leadersh. $Q$. 2015, 26: 1034-1050. doi:10.1016/j.leaqua.2015.07.004.

[17] J.A. Kennedy, C. Anderson, Hierarchical rank and principled dissent: How holding higher rank suppresses objection to unethical practices, Organ. Behav. Hum. Decis. Process. 2017, 139: 30-49. doi:10.1016/j.obhdp.2017.01.002.

[18] M. Mooijman, W.W. van Dijk, N. Ellemers, E. van Dijk, Why leaders punish: A power perspective, J. Pers. Soc. Psychol. 2015, 109: 75-89. doi:10.1037/pspi0000021.

[19] M. Mooijman, W.W. van Dijk, E. van Dijk, N. Ellemers, On sanction-goal justifications: How and why deterrence justifications undermine rule compliance, J. Pers. Soc. Psychol. 2017, 112: 577 588. doi:10.1037/pspi0000084.

[20] S. Bendahan, C. Zehnder, F.P. Pralong, J. Antonakis, Leader corruption depends on power and testosterone, Leadersh. Q. 2015, 26: 101-122. doi:10.1016/j.leaqua.2014.07.010.

[21] L. Giurge, M.H. van Dijke, X. Zheng, D. De Cremer, Power corrupts the mind? Power lowers moral reasoning level. Leadersh. $Q$. (in press).

* This article studies the corrupting influence of power using a design that avoids results being driven by demand characteristics and that do not use deception

[22] T.A. Foulk, K. Lanaj, M.-H. Tu, A. Erez, L. Archambeau, Heavy is the head that wears the crown: An actor-centric approach to daily psychological power, abusive leader behavior, and perceived incivility, Acad. Manage. J. 2018, 61: 661-684. doi:10.5465/amj.2015.1061.

* This article shows that power predicts increased abusive leader behavior but this abuse also predicts subsequent decreases in the leader's own wellbeing.

[23] E.X.M. Wee, H. Liao, D. Liu, J. Liu, Moving from abuse to reconciliation: a power-dependence perspective on when and how a follower can break the spiral of abuse, Acad. Manage. J. 2017, 60: $2352-2380$. doi: $10.5465 / \mathrm{amj} .2015 .0866$.

* This article shows how followers can build power over their leader (e.g., by forming coalitions) to decrease the leaders' abusive behavior.

[24] P.K. Smith, W. Hofmann, Power in everyday life, Proc. Natl. Acad. Sci. U. S. A. 2016, 113: 1004310048. doi:10.1073/pnas.1604820113.

* This article takes studies power outside of the contexts in which it is traditionally studies: the laboratory and work organizations, and shows that in everyday life, power can have effects that are different from those obtained in traditional contexts.

[25] R.G. Swab, P.D. Johnson, Steel sharpens steel: A review of multilevel competition and 
competitiveness in organizations., J. Orb. Beh. 2019, 40: 147-165.

[26] M. Schaerer, C. du Plessis, A.J. Yap, S. Thau, Low power individuals in social power research: A quantitative review, theoretical framework, and empirical test, Organ. Behav. Hum. Decis. Process. 2018, 149: 73-96. doi:10.1016/j.obhdp.2018.08.004.

[27] F. Wang, X. Sun, Absolute power leads to absolute corruption? Impact of power on corruption depending on the concepts of power one holds, Eur. J. Soc. Psychol. 2016, 46: 77-89. doi:10.1002/ejsp.2134.

[28] F.R.C. De Wit, D. Scheepers, N. Ellemers, K. Sassenberg, A. Scholl, Whether power holders construe their power as responsibility or opportunity influences their tendency to take advice from others, J. Organ. Behav. 2017, 38: 923-949. doi:10.1002/job.2171.

* This article provides a good illustration of the crucial role of construal (rather than level) of power, in this case showing that construing power as responsibility makes leaders more willing to accept advice from others.

[29] Schmid Mast, M., Khademi, M., Palese, T., Power and social information processing, Curr. Opin. Psychol. this issue. [30] A. Scholl, K. Sassenberg, D. Scheepers, N. Ellemers, F. de Wit, A matter of focus: Power-holders feel more responsible after adopting a cognitive other-focus, rather than a self-focus, Br. J. Soc. Psychol. 2017, 56: 89-102. doi:10.1111/bjso.12177.

[31] A. Scholl, K. Sassenberg, N. Ellemers, D. Scheepers, F. de Wit, Highly identified power-holders feel responsible: The interplay between social identification and social power within groups, $B r$. J. Soc. Psychol. 2018, 57: 112-129. doi:10.1111/bjso.12225.

[32] L.P. Tost, K.A. Wade-Benzoni, H.H. Johnson, Noblesse oblige emerges (with time): Power enhances intergenerational beneficence, Organ. Behav. Hum. Decis. Process. 2015, 128: 61-73. doi:10.1016/j.obhdp.2015.03.003.

[33] G.S. Leventhal, What should be done with equity theory?, in: Soc. Exch., Springer, 1980: pp. 2755.

[34] Y. Cohen-Charash, P.E. Spector, The role of justice in organizations: A meta-analysis, Organ. Behav. Hum. Decis. Process. 2001, 86: 278-321.

[35] J.A. Colquitt, On the dimensionality of organizational justice: A construct validation of a measure., J. Appl. Psychol. 2001, 86: 386-400.

[36] E.P. Karam, J. Hu, R.B. Davison, M. Juravich, J.D. Nahrgang, S.E. Humphrey, D.S. DeRue, Illuminating the 'face' of justice: a meta-analytic examination of leadership and organizational justice, J. Manag. Stud. 2019, 56: 134-171. doi:10.1111/joms.12402.

[37] M. van Dijke, D. De Cremer, D.M. Mayer, The role of authority power in explaining procedural fairness effects, J. Appl. Psychol. 2010, 95: 488-502. doi:10.1037/a0018921.

[38] E.N. Sherf, V. Venkataramani, R.S. Gajendran, Too busy to be fair? The effect of workload and rewards on managers' justice rule adherence, Acad. Manage. J. 2018

[39] S. Chen, A. Lee-Chai, J. Bargh, Relationship orientation as a moderator of the effects of social power, J. Pers. Soc. Psychol. 2001, 80: 173-187. doi:10.1037//0022-3514.80.2.173.

[40] K.A. DeCelles, D.S. DeRue, J.D. Margolis, T.L. Ceranic, Does power corrupt or enable? when and why power facilitates self-interested behavior, J. Appl. Psychol. 2012, 97: 681-689. doi:10.1037/a0026811.

[41] S.L. Blader, Y.-R. Chen, Differentiating the effects of status and power: A justice perspective, $J$. Pers. Soc. Psychol. 2012, 102: 994-1014. doi:10.1037/a0026651.

[42] A.D. Galinsky, J.C. Magee, D. Rus, N.B. Rothman, A.R. Todd, Acceleration with steering: the synergistic benefits of combining power and perspective-taking, Soc. Psychol. Personal. Sci. 2014, 5: 627-635. doi:10.1177/1948550613519685.

[43] M.K. Chin, D.C. Hambrick, L.K. Trevino, Political ideologies of CEOs: The influence of executives' values on corporate social responsibility, Adm. Sci. Q. 2013, 58: 197-232. doi:10.1177/0001839213486984.

[44] Y. Kalish, G. Luria, Leadership emergence over time in short-lived groups: Integrating expectations states theory with temporal person-perception and self-serving bias, $\mathrm{J}$. Appl. Psychol. 2016, 101: 1474-1486. doi:10.1037/apl0000126. 
[45] W. de Waal-Andrews, A.P. Gregg, J. Lammers, When status is grabbed and when status is granted: Getting ahead in dominance and prestige hierarchies, Br. J. Soc. Psychol. 2015, 54: 445464. doi:10.1111/bjso.12093.

[46] C.C. Locke, C. Anderson, The downside of looking like a leader: Power, nonverbal confidence, and participative decision-making, J. Exp. Soc. Psychol. 2015, 58: 42-47. doi:10.1016/j.jesp.2014.12.004.

[47] J. Mao, C.-Y. (Chad) Chiu, B.P. Owens, J.A. Brown, J. Liao, Growing followers: Exploring the effects of leader humility on follower self-expansion, self-efficacy, and performance, J. Manag. Stud. 2019, 56: 343-371. doi:10.1111/joms.12395.

[48] B.P. Owens, D.R. Hekman, How does leader humility influence team performance? Exploring the mechanisms of contagion and collective promotion focus, Acad. Manage. J. 2016, 59: 1088-1111. doi:10.5465/amj.2013.0660.

[49] A. Rego, B. Owens, S. Leal, A.I. Melo, M. Pina e Cunha, L. Goncalves, P. Ribeiro, How leader humility helps teams to be humbler, psychologically stronger, and more effective: A moderated mediation model, Leadersh. Q. 2017, 28: 639-658. doi:10.1016/j.leaqua.2017.02.002.

[50] A.Y. Ou, D.A. Waldman, S.J. Peterson, Do humble CEOs matter? An examination of ceo humility and firm outcomes, J. Manag. 2018, 44: 1147-1173. doi:10.1177/0149206315604187.

* This article shows relationships between CEO humility and objective indices of firm performance, as mediated by dynamics within the top management team.

[51] A. Guinote, The social cogntion of power, APA Handb. Personal. Soc. Psychol. 2015, 1: 547-569.

[52] J. Overbeck, B. Park, Powerful perceivers, powerless objects: Flexibility of powerholders' social attention, Organ. Behav. Hum. Decis. Process. 2006, 99: 227-243. doi:10.1016/j.obhdp.2005.10.003.

[53] M. van Dijke, D. De Cremer, G. Langendijk, C. Anderson, Ranking low, feeling high: How hierarchical position and experienced power promote prosocial behavior in response to procedural justice, J. Appl. Psychol. 2018, 103: 164-181. doi:10.1037/apl0000260.

* This article shows that experiencing high (vs. low) power makes organization members act more upon contextual antecedents of prosocial behavior (i.e., procedural fairness); being in a high (vs. low) structural power position has the opposite effect.

[54] D. Kipnis, S. Schmidt, I. Wilkinson, Intraorganizational influence tactics - Explorations in getting ones way, J. Appl. Psychol. 1980, 65: 440-452. doi:10.1037//0021-9010.65.4.440.

[55] B. Oc, M.R. Bashshur, C. Moore, Speaking truth to power: The effect of candid feedback on how individuals with power allocate resources, J. Appl. Psychol. 2015, 100: 450-463. doi:10.1037/a0038138.

* This article shows that followers do not need power to decrease leader abuse. Providing accurate feedback about the leader's level of self-interest reduces subsequent self-interested leader behavior.

[56] B. Oc, M.R. Bashshur, C. Moore, Head above the parapet: How minority subordinates influence group outcomes and the consequences they face for doing so., J. Appl. Psychol. 2019. doi:10.1037/apl0000376.

[57] H. Liu, J.T.-J. Chiang, R. Fehr, M. Xu, S. Wang, How do leaders react when treated unfairly? Leader narcissism and self-interested behavior in response to unfair treatment, J. Appl. Psychol. 2017, 102: 1590-1599. doi:10.1037/ap10000237.

[58] D. Liu, H. Liao, R. Loi, The dark side of leadership: A three-level investigation of the cascading effect of abusive supervision on employee creativity, Acad. Manage. J. 2012: 55 1187-1212. doi:10.5465/amj.2010.0400.

[59] B. Tepper, E. Taylor, Relationships among supervisors' and subordinates' procedural justice perceptions and organizational citizenship behaviors, Acad. Manage. J. 2003, 46: 97-105. doi:10.2307/30040679.

[60] D.X. Wo, M. Schminke, M.L. Ambrose, Trickle-down, trickle-out, trickle-up, trickle-in, and trickle-around effects: An integrative perspective on indirect social influence phenomena, $J$. Manag. 2018, 0149206318812951.

* This article offers an in depth review of trickle down research, showing what we know and what we don't know (e.g., we don't know much about processes that explain trickle down effects). 
[61] G. van Houwelingen, M. van Dijke, D. De Cremer, Fairness enactment as response to higher level unfairness: The roles of self-construal and spatial distance, J. Manag. 2017, 43: 319-347. doi:10.1177/0149206314530166.

[62] F.J. Flynn, D. Gruenfeld, L.D. Molm, J.T. Polzer, Social psychological perspectives on power in organizations, Adm. Sci. Q. 2011, 56: 495-500. doi:10.1177/0001839212440969.

[63] R.E. Sturm, J. Antonakis, Interpersonal power: a review, critique, and research agenda, J. Manag. 2015, 41: 136-163. doi:10.1177/0149206314555769.

[64] J. Antonakis, S. Bendahan, P. Jacquart, R. Lalive, Causality and endogeneity: Problems and solutions, Oxf. Handb. Leadersh. Organ. 2014, 93. 


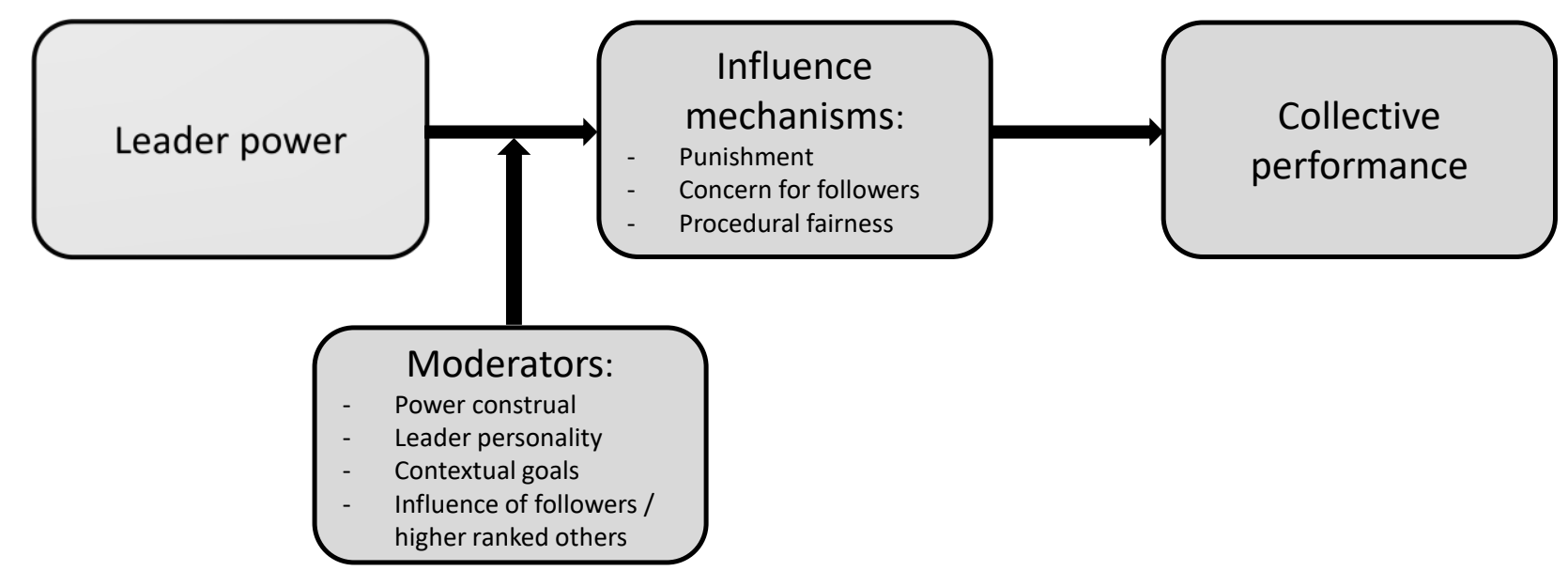

Figure 1. How leader's power influences collective performance depending on various moderators. 